\title{
Playfulness in Children's Picture Books about Bedtime: Ambivalence and Subversion in the Bedtime Story
}

\author{
Kathlyn Griffith and Jane Torr
}

I n children's picture books, the connection between play and the rituals associated with bedtime is frequently addressed. Despite the fact that bedtime would seem to have little connection with play, play is a significant element in the construction of meaning in those books that focus on that period of the day. Play is embedded in bedtime picture books in many ways, through the qualities of the written language and the illustrations, and through narrative sequences. Child characters are frequently depicted as engaging in physical play, either literally before they go to sleep or in their dreams and fantasies. The notion that play is central in children's lives is reinforced by countless references to play in illustrations, with images of teddies, dolls, bicycles, balls, balloons, swings, puppets, kites and other playthings commonly appearing. The written language in many bedtime picture books is full of language play, which resonates with young children's own playful use of language (Chukovsky 1971, Garvey 1990, Grainger and Gooch 1999). Rhyme, repetition, distinctive rhythms, alliteration, assonance, onomatopoeia, unusual vocabulary and nonsense elements are used for playful, poetic and sometimes humorous effect in these books. Stephens (1992) affirms the centrality of play by noting that children's literature is itself inherently playful, as it is 'grounded in playfulness' (p.121). Significantly for this paper Stephens also states that playfulness is often used to express 'opposition to authoritarianism and seriousness' (p. 121). This paper will argue that these two elements, playfulness on the one hand and opposition to authority and seriousness on the other, are a fundamental feature of bedtime picture books.

Play is an activity that fills children's lives and is one of the major ways children construct their understanding of the world. While there are many definitions of what play is there is some consensus among theorists that it has certain recognisable characteristics. It is pleasurable, symbolic, meaningful, active, voluntary, rule governed and episodic (Fromberg 1992). There is also consensus that play is context dependent. Where, with whom, when and why a child plays influences the type and the range of play activities a child is likely to engage in. According to Isenberg and Jalongo (2001), play allows children to become empowered, to feel in control, to test their ideas and understandings, and to develop a sense of competence and confidence. In literature for young children it is used as a vehicle for exploring a range of issues pertinent to the young child's life. Max in Sendak's Where the Wild Things Are (1970), Olivia in Falkoner's Olivia Saves the Circus (2001), and many of John Burningham's characters use imaginative play to come to terms with their emotional and psychological needs. Bob Graham's books consistently depict children engaged in playful activities in the context of family life as a way of celebrating that particular context. Anthony Browne uses visual play to engage his audience and to give some definition to his protagonists' dilemmas. Alphabet books often employ a playful approach to involve children in the process of learning the alphabet. A good example of this is Martin Jnr, Archambault and Ehlert's Chicka Chicka Boom Boom (1989) where the alphabet letters, as characters in their own right, are playfully engaged in a series of adventures invitingly described in equally playful rhymed language.

Play in children's books is seen in a particular context. It is highly romanticised in that it rarely depicts either visually or verbally many of the real play experiences children are likely to participate in. Rough and tumble play, play squabbles, children being excluded from play can be seen in some literature for young children but they are rare when compared to the number of examples of children happily playing within the supportive family context.

The differences between children's and adults' perspectives about what is appropriate behaviour at bedtime have the potential for conflict and power struggles. Those behaviours that the adult desires and often demands (silence, compliance, and an insistence that the daytime activities, notably play, have no place at bedtime) are in contrast with the views of many young children who find it much more difficult to abandon those playful behaviours that have filled their day. These differing perspectives are made more complex still because bedtime picture books are written by adults for children, and are read by adults to children who are usually going to bed at the time of reading. It is a complex context in which adults, who want to promote a particular response from children, use books 
which depict children engaged in playful activities which seemingly contradict the purpose of settling the child to sleep.

For many families in western cultures, the bedtime story plays a central role in an evening ritual, which culminates in small children going to bed and, theoretically, to sleep for the night. There is therefore a unique relationship between the physical and social context in which the story itself is read (the child is literally in bed) and the written text and images portrayed in bedtime picture books. It is a context that demands a particular physical response because the bedtime story is usually seen as serving the function of settling the child for the night, somewhat like a lullaby, and facilitating the child's transition from wakefulness to sleep. Yet bedtime raises many complicated issues for adults and children alike. That this is so is evidenced by the complex rituals associated with bedtime in many homes, the special clothing (pyjamas), the beloved ritual objects (soft toy, night light) and the processes of bathing and brushing teeth (physical cleansing). The issues surrounding these rituals may in part account for the ubiquity of books about bedtime, and also for the fact that the messages conveyed in these books are often ambiguous and subversive.

Bedtime is an area of cultural and emotional significance for adults and children alike, in that it poses uncomfortable and difficult questions about the human condition. In many religious and literary traditions, for example, night and sleep are used as metaphors for death, and this metaphorical association is hinted at in lullabies such as 'Rock a bye baby', and in the illustrations of some bedtime books, for example Boynton's simple narrative The Going to Bed Book (1985) which is set on a boat resembling Noah's ark. In order to go to sleep, it is necessary for children to let go of everyday activities, including play, to lose consciousness and thus to become vulnerable. Night cannot be postponed or ignored, even by the youngest members of society who are often expected to sleep alone in a dark room with restrictions on their physical movements. This contrasts with their daytime activities when they are constantly under adult supervision. Bedtime picture books are used either consciously or unconsciously by adults to give clues to children as to how they might imagine and make sense of this paradox and the inherent ambiguities and potential conflicts that this foregrounds.

The five picture books selected for this study were chosen from a corpus of some thirty bedtime books written during the last sixty years by well known and highly regarded authors and illustrators. While Moebius argues that 'any book, in the right circumstances, can lull the reader to sleep' (1991, p.53), there are nonetheless books specifically designed to achieve this end. In Wise Brown and Hurd's (1947, 1975) Goodnight Moon and Waddell and Firth's (1988) Can't You Sleep, Little Bear? verbal play and physical play respectively are used as powerful tools by the child to extend the period of wakefulness. In Wild and James' (1996) The Midnight Gang and Waddell and Firth's (1989) The Park in the Dark the potential of sleep to involve the child in the rich world of fantasy play is seen perhaps as a self imposed inducement to sleep. These books are contrasted with Raschka's (1995) more serious Can't Sleep, in which the absence of play is a distinguishing characteristic.

It is common for bedtime picture books to depict play as a means of making the transition from being awake to being asleep. In Goodnight Moon and Can't You Sleep Little Bear?, for instance, the child is already in bed or at least in the bedroom. The problem is how to make the transition from being awake to being asleep. This is not just a problem for the child, but also for the adult who is keen to move to the period when the child is asleep. The child knows this and therefore has some power to manipulate this situation. Goodnight Moon and Can't You Sleep Little Bear? are texts which acknowledge the role of play in that time between waking and sleeping, day and night.

Verbal play in Goodnight Moon and physical play in Can't you Sleep Little Bear? are used to delay and manage the onset of that long period of sleep where presumably play is not possible. Play becomes a tool in the hands of children who try to control a situation over which they can have temporary control, but ultimately no control. In Goodnight Moon the rabbit tries to delay the inevitable by using a form of language play. As the room becomes slightly darker in each colour double-page 
spread, we see the small rabbit turning and moving in his bed as he says goodnight to all the elements in his familiar world. As sleep approaches, as evidenced by the turning hands of the clock, the darkening room and the slightly lowered eyelids of the rabbit, he bids a playful 'Goodnight nobody, Goodnight mush' before a final, serious 'And goodnight to the old lady whispering "hush"'. Contrary to Galbraith's suggestion that this rhyme could convey 'despair and bitterness' (1998-99, p.175), such language resonates with the language play typical of young children (Crystal 1995, Garvey 1990, Ely and McCabe 1994). In the last two double-page spreads, the rabbit's thoughts move beyond the small world of his bedroom and into the universe in the words 'Goodnight stars, Goodnight air, Goodnight noises everywhere', and we see him asleep at last.

In Goodnight Moon, the child deals with the necessity of having to go to sleep by creating a ritual of his own. Even though there is an adult present she is nothing more than an observer, a silent patient presence who accepts the playful behaviour of the child. There is no tension or threat of tension in this text. The description of both the adult and the child's behaviour suggests that this is an oftrepeated ritual. It is the way the child gets to sleep. The verbal naming of objects on the 'goodnight list' is soothing in its predictability and serves a meditative function. While some names are gently humorous, like 'goodnight air', they never upset the calm soporific effect of their chant-like quality. Confined to his bed, unable to or prevented from physically playing, the rabbit nonetheless uses verbal play (permitted by the adult present) as a way of effectively managing this transitional period. It is a clear representation of what Meek (1985, cited in Grainger and Gooch 1999, p. 49) describes as children 'reordering things in their heads if not in fact.

In Can't You Sleep Little Bear? the delaying tactics of Little Bear are more ambiguous. The reader cannot be certain that the reluctance to sleep is truly related to a fear of the dark 'out there' or whether it is simply an excuse for more play, for testing the adult, for pushing the boundaries. Clearly Little Bear, like the rabbit in Goodnight Moon and the dog in Can't Sleep, knows that there are restrictions placed on his behaviour because it is bedtime. In each opening where Little Bear is depicted as playing, it is always on his bed. Even when he questions the darkness 'out there', it is always seen from the perspective of his bed. Like the rabbit he confines his play to his bed but unlike his counterpart in Goodnight Moon his play is physical as he jumps, twists, and somersaults in his vain attempt to sleep.

Consistent with what often happens in children's play outside this context, there is an element of risk in Little Bear's challenging behaviour. Children take chances in play as they test themselves and others in a range of situations and with a range of others. There is more risk in this context because it has been encountered before and the challenge for Little Bear is to know how far to go in his playful attempts to ward off the darkness and the inevitability of sleep. Just how much can Little Bear subvert Big Bear's attempt to read his book 'right to the end'? How far can the balance of power through play be manipulated?

In contrast to Goodnight Moon, there are levels of tension in this narrative. The obvious tension is that between Big Bear and Little Bear as each 'tries' to settle down at the end of the day. The illustrations depict Big Bear looking increasingly tired as he responds to Little Bear's continuing demands. There is also that tension hinted at in many books dealing with this topic that sleep for children marks the beginning of a new set of activities for the adult from which the child is excluded. An example would be Hoban and Williams' (1976) Bedtime for Francis. From the child's point of view the adults can continue to play while the child must sleep.

There is, however, an ambiguity in Can't You Sleep Little Bear?, in the sense that, despite all Big Bear's efforts to encourage Little Bear to go to sleep in his bed, the final frame depicts the child asleep in his parent's arms. This conclusion subtly validates the child's perspective that he or she should not have to conform to adult expectations by going to sleep in his or her bed, and that it is acceptable to subvert the adult's desire to play. It does not provide the child reader with any creative or imaginative strategies for dealing with the important issues raised by bedtime, except for the manipulation of the adult. This is in 
contrast to the behaviour of many children depicted in bedtime picture books.

Another group of books about bedtime focuses on the nature of sleep itself, and the imagined play experiences possible during sleep, rather than on the role of play in making the transition from wakefulness to sleep. The Midnight Gang and The Park in the Dark depict a type of fantasy play which becomes possible in the child's dreamscape after he or she has fallen to sleep. These books suggest that the child may respond to the 'problem' of bedtime and night by engaging in a range of imaginative playful experiences when asleep. Drawing on the generic features of fantasy literature - the witching hour, magic events, midnight, the coming to life of inanimate objectsthey suggest that once the child is asleep a different kind of play becomes possible. Play now transcends the child's everyday physical limitations and the power of the adult to control their behaviour. Only when the child is physically asleep is the child able to engage in this type of play. Play in these texts is a way of subverting adult control. In both these books the children are depicted as engaging in dangerous play which would normally only be permitted with adult supervision, for example visiting the park alone and at night, swinging in a way which would be seen as reckless by adults.

The language in these books is both playful and about play, for example the rhyme and repetition which accompanies the image of the animated toy 'children' swinging joyously in The Park in the Dark reads, 'And we swing and we slide and we dance and we jump and we chase all over the place, me and Loopy and Little Gee, the Big Three!', inviting the adult reader to play with the patterns and rhythms of the text as they read aloud. When the toys' fun turns to fear the text reads 'And then the THING comes! YAAAAA AAAIII OOOOOEEEEEEE!', again encouraging adult readers through the font and capitalization to use playfully exaggerated tones and intonations in their reading.

In The Park in the Dark, there is the suggestion that children in their fantasies are deliberately challenging what, from the adult's perspective, is acceptable behaviour for children. This interpretation is verified by the appearance of the train, which symbolises both the danger which parents would normally protect them from, and the power of the adult world in the lives of the young. There is subconscious acknowledgement of the train's meaning as the children retreat to the safety of their bedroom and their dreamless state. While play is central to the child's world, as already stated, there is an acknowledgement in this text that play must be safe to be enjoyed, and safety implies an adult presence.

In The Midnight Gang, baby Brenda is not deliberately flouting adult authority in her play. She does not yet know how the world works. Her play is beyond what is known. The book represents an innocent child whose fantasy play knows no bounds. Anything is possible, as she removes her nappy and climbs through the cat-flap. During sleep, the child can transcend the physical laws of time and space. Even the elements of the universe, the stars, moon and comets are transformed into a small child's playthings. Yet this book is not just about baby Brenda's play, as the implied child and adult reader are also invited to engage in word play throughout the text: the print varies in size, shape, position and direction, reflecting the exuberant physical play of the toddler gang, and the language is playful with onomatopoeic expressions encouraging the adult reader to use exaggerated tone and intonation for humorous effect (whoosh, schrieking, creaky-cracky). There is also the humour which arises from the juxtaposition of baby Brenda's world view and that of the more knowledgeable child reader. To Brenda, the family dog is a 'slobbering monster' and the cat is a 'hairy beast'. We share a joke with baby Brenda at the end, when her mother and sister assure her that one day she will be old enough to have a little swing.

In contrast to many books about bedtime for young children is Chris Raschka's Can't Sleep. This is a text in which play is absent. Can't Sleep features a different sort of child, one who is clearly not testing or confronting an adult or expecting that the major activity of the day, play, will be continued. Play simply does not feature; perhaps it is no longer an option for this child who is older than those depicted in Goodnight Moon, The Park in the Dark and The Midnight Gang. This playless approach, which is significant in defining its distinctiveness, suggests that it is a much more complex and serious narrative that 
challenges the ways this topic is usually depicted in picture books. A different level of meaning is being addressed here, because the child is older and can begin to understand the cultural expectations of how he or she should behave at this time of day. With its spare but evocative text and illustrations this book attempts to describe to the young child through a series of matter-offact statements about what will happen up to and during this extended period of darkness. While it makes use of familiar nighttime signifiers; the moon, the bedroom context, the small rituals associated with going to bed, it does so in an unconventional way.

Firstly the moon is not just a passive observer, or symbol of the night, but is an active participant in the process of going to sleep. Secondly, the inclusion and participation of the whole family in this process is important. The suggestion found in many similar texts that bedtime for children marks the beginning of playtime for adults is simply not there. Parents and siblings have to come to terms with this altered state of consciousness, as does the child at the centre of the action. And, finally, there is the nature of the reciprocal relationship of care present between the child and the moon. Both assume the roles of surrogate mother/guardian angel guiding and protecting each other through night and day.

The cyclical nature of the description/explanation has a rhythmic patterning that captures the natural rhythm of the world turning on its axis, moving between night and day, day and night. Just as there is inevitability to the movement of the world there is inevitability to this ritual of behaviour. It is simply part of the expected patterning or ordering of events. This is reflected in the calm, comforting and gently confirming lullaby-like intonation of the text which suggests that what is being explored is part of the natural order of things. It needs to be talked about and it needs to be accepted. What is implied in this book is that what is being described is different to what happens at times during the day. While, as the cover notes state, this is a book which draws parallels between inside and outside, alone and together, a child's room and the universe, these places and states of mind have a definition that is exclusive to this time and place. Outside, at night, is not a place where exciting things happen or where another dimension of play exists as it does in The Park in the Dark. 'Outside' in this text, except for the presence of the moon, is a place of 'nothingness' which is perhaps, potentially and paradoxically, as unsettling as it might be calming. The only relationship that exists in this empty darkness is that between the child and the watchful moon. This is how it is.

This notion of acceptance of what is normal at this specific time of day is evident throughout, as the text never attempts to offer an explanation of why this is so. It simply states what happens: 'When you can't sleep the moon will keep you safe. The moon will stay awake'. The repetition of the word will implies that these are statements of fact to be accepted and believed. This quietly confident and affirming narrative voice, however, does not shy away from the reality of the situation: the sense of isolation, the aloneness, or the lack of support from those you would expect to comfort you at this time, that is, your parents, your family members: 'Now when there is no sound the moon can tell you feel frightened and are lonely. The moon will stay awake for you'. There is no suggestion here that play could be used as a way of staving off these fears, of easing the transition between night and day, dark and light, what is known and unknown.

The issue of who is speaking is complex in this text. At least three possible voices may be discerned. One possibility is the omniscient narrator, one who is removed from the events unfolding, but who is aware of their significance ('Now when there is no sound ... The moon will stay awake for you until you too are sleeping'). A second possibility is that it is the inner voice of the child, as evident in the monitoring of what will happen and what he has to do. The third possibility is that these are the internalised voices of the parents which the child is repeating to him or herself ('When your big brother goes to bed and sleeps and you can't sleep, the moon will watch you in your room'). Whichever narrative voice the reader/listener acknowledges, the narrator of this tale nonetheless directly addresses a particular child-like character (a dog). This, as well as the fact that the child is an 'every' child, not defined by race or gender, insists on the universality of the experience. The inclusive way all readers/listeners are drawn into the narrative reinforces 
the central tenet of the book which implies that wherever you are, whatever your circumstances, you are not alone in your response to this situation. That this is so is given further support through the illustrations which position the reader/viewer outside the action, looking down on the both the moon and the child and its family. This reinforces the notion of the naturalness of this sequence of events, which we loosely define as bedtime and which links all children through this child.

As in all quality picture books the text and the illustrations carry the narrative. The illustrations with their restricted palette are dominated by the cool deep blue of the night, which surrounds everything, and the warm yellows of the domestic scenes and, significantly, the moon. The golden face of the moon 'asleep' in the lower left-hand corner of the title page slowly but inevitably travels up, across and over the child on its journey of watchful care. As it moves across the pages its face responds to the behaviour depicted in the household below suggesting a very personal relationship with the characters in its domain; concern when the child still can't sleep, smiling when watching the child snuggle under covers and awake when 'staying awake for you', and finally kissing the child when sleep has been achieved. When it has fulfilled its function of care it is located in the lower right hand corner of the page, eyes closed, safe in the knowledge that it is now time for 'you' to keep her (the moon) safe. Safe from what is never defined but throughout the book the assumption is that children and families need to be protected in this period. On the final page both characters, moon and child, are now completely unrestrained by the shapes that have contained and defined them throughout the book. They are as one as the shift in roles is about to take place.

The domestic scenes the moon watches over, while focussing on the child, include the whole family. This is an important inclusion and is another feature that distinguishes this text from many others that deal with the same subject matter. The bedtime/nightime rituals of the family are described as a natural series of events which are as predictable as the circular journey of the moon; father turning off the lights, mother moving in the hall and bathroom, the closing of doors. The small details that define this ritual and the minutiae of family life are visually and verbally described as the family prepares for sleep. As each member of the family falls asleep the frame of yellow light surrounding and isolating them from each other disappears as they become part of a larger community of sleepers. The moon and stars enclose them in a clear depiction of their place in the universe. In a gesture of love the moon kisses the child now fast asleep in the deep blue of night. The moon's work is done and now she too can close her eyes as the world edges toward morning.

It is as though the text is offering a rational solution to the problem that is bedtime in our society. And the solution is that the child has to accept that this is the way it is; no play, no fun, no games and, past a certain point, no family support. The moon is there to affirm the truth of this understanding but not to change it. What is also true is that the moon will not always be visibly present to support the child in such a physical way. Her presence will have to be imagined.

This is a deeply imagined text about respect and acceptance in which play as we know and understand it has no part. Opportunities abound in the visual and verbal texts for play to intrude creating a more lighthearted approach. The most obvious here is in the potential for playfulness in the anthropomorphised dog. Such opportunities, however, are never realised, as page by page the reader becomes more deeply embedded and involved. Perhaps the only playful element of this book is the title. The unpunctuated Can't Sleep on the cover and title page is set beside the illustration of the moon, which is unambiguously depicted as being asleep. It is difficult to determine whether the title is ironic or sarcastic; whether it is a question or a statement.

Contrary to this affirmative reading of Can't Sleep is Galbraith's assertion that it is 'the least reassuring bedtime book I've come across' (1998-99, p.177). Galbraith bases her interpretation on the link between attachment theory and the child's need for support, especially that of the 'sustained bodily contact with the parent in times of stress' (p.177). While this might be so, she fails to demonstrate that this particular child is stressed. When making a case for what Walant describes as 'normative abuse' (Walant 1995, cited in Galbraith 1998-99, p. 178), 
Galbraith uses such emotionally charged words as 'imprisoned' and 'intrusive' to support her argument. There is, however, no evidence in the visual or verbal text to support this extreme view.

What Galbraith fails to acknowledge is the implied age of this child. As already noted, the dog child is significantly older than the one depicted in Good Night Moon. Children of this age, around six to eight years, are in fact generally expected within Western culture to go to sleep independently of the adults who care for them. Sustained bodily contact is not an expectation except in times of acute stress, for example when the child is sick or has had a nightmare. Instead, in Can't Sleep, there is a child who is growing in self sufficiency, beginning to see beyond his or her dependence on others and moving to the point of acknowledging the value of reciprocal care, as in the final lines 'Now you may stay awake and keep her safe ... you'll keep her safe'. Although not without some element of anxiety, in the end this bedroom 'betokens the restoration of calm and the absence of confusion or anxiety' (Moebius 1991, p.55). Can't Sleep is ultimately a book 'designed to help children, psychologically and emotionally' (Stallcup 2002, p.127) by empowering them and offering 'a model in which children overcome their fear not simply through relying on adults but through developing adultlike characteristics themselves' (Stallcup 2002, p.127).

What emerges from this reading of these texts is the complex and ambiguous nature of this common ritual and theme in child's bedtime picture books. There is much more that remains to be explored, including the range and use of religious allusions and symbols embedded in these books. Play is not as simple and straightforward as it may appear. Play is what children do, and because of this it is a powerful vehicle for interpreting, challenging and resolving the important issues in their lives.

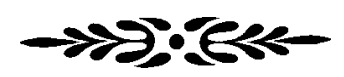

\section{REFERENCES}

Boynton, Sandra (1995) The Going to Bed Book. New York, Simon and Schuster.

Brown, Margaret Wise and Hurd, Clement (1947, 1975) Goodnight Moon. New York, Harper Trophy.

Crystal, David (1995) 'From babble to scrabble: integrating language creativity and linguistic intervention', in John Murray (ed) Celebrating Differences: Confronting Literacies. South Carlton, Vic: Australian Literacy Educators' Association, pp.45-66.

Chukovsky, Kornei (1971) From Two to Five. (rev. ed.) Berkeley, University of California Press.

Ely, Richard and McCabe, Allyssa (1994) 'The language play of kindergarten children', First Language 14, 19-35.

Falkoner, Ian (2001) Olivia Saves the Circus. New York, Atheneum.

Fromberg, Doris (1992) 'A review of research on play', in Carol Seefeldt (ed) The Early Childhood Curriculum: A Review of Current Research ( $2^{\text {nd }}$ ed.). New York, TC Press, pp.42-84.

Galbraith, Mary (1998-99) 'Goodnight Nobody revisited: Using an attachment perspective to study picture books about bedtime', Children's Literature Association Quarterly 23, 4: 172-180.

Garvey, Catherine (1990) Play (2 ${ }^{\text {nd }}$ ed.) Cambridge, Mass., Harvard University Press.

Grainger, T. and Gooch, K. (1999) 'Young children and playful language', in Tricia David (ed) Teaching Young Children. London, Paul Chapman, pp.19-29.

Hoban, Russell and Williams, Garth (1976) Bedtime for Frances. Harmondsworth, Puffin Books. 
Isenberg, Joan and Jalongo, Mary (2001) Creative Expression and Play in Early Childhood ( $3^{\text {rd }}$ ed.). Upper Saddle River, N.J., Merrill.

Martin, Bill Jr, Archambault, John and Ehlert, Louise (1989) Chicka Chicka Boom Boom. New York, Simon \& Schuster Books for Young Readers.

Moebius, William (1991) 'Room with a view: bedroom scenes in picture books', Children's Literature 19: 53-74.

Raschka, Chris (1995) Can't Sleep. New York, Orchard Books.

Sendak, Maurice (1970) Where the Wild Things Are. London, Bodley Head.

Stallcup, Jackie. E. (2002) 'Power, fear, and children's picture books', Children's Literature 30: 125-262.

Stephens, John (1992) Language and Ideology in Children's Fiction. London, Longman.

Waddell, Martin, and Firth, Barbara (1988) Can't You Sleep, Little Bear? London, Walker Books.

Waddell, Martin, and Firth, Barbara (1989) The Park in the Dark. London, Walker Books.

Wild, Margaret, and James, Ann (1996) The Midnight Gang. Norwood, SA, Omnibus Books.

\section{BIOGRAPHICAL NOTES}

Kathlyn Griffith is a lecturer in play and children's literature at the Institute of Early Childhood, Macquarie University. She has a long term interest in the relationship between text and illustration and particularly illustrations of nursery rhymes and poems. With Clare Scott- Mitchell she has recently edited 100 Australian Poems for Children.

Jane Torr is a senior lecturer in language, literacy and children's literature at the Institute of Early Childhood, Macquarie University. Her research interests and publications are in the areas of early language development, adult/child talk surrounding the reading of picture books and children's literature.

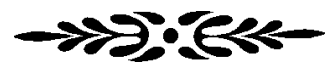

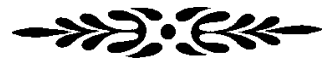

